\title{
Endeudamiento y ahorro del personal en la gestión de los bienestares institucionales ${ }^{1}$ Indebtness and savings as part of employees assistance program management ${ }^{1}$
}

\author{
IsABel MonCKeberg ${ }^{2}$
}

\begin{abstract}
Resumen
El objetivo de este artículo es compartir con los trabajadores sociales, elementos de diagnóstico en el tema del endeudamiento y ahorro, siendo el sobreendeudamiento una temática especialmente emergente en los últimos años. También lo es el ahorro, dado los nuevos incentivos que se dan para su fomento. Ambas variables son las distintas caras de un trabajo en la temática económica que puede efectuarse a partir de las organizaciones de bienestar en las instituciones laborales.

Palabras claves: endeudamiento - ahorro - gestión de bienestar - organizaciones sociales

Abstract

This article seeks to share with social workers some usefull tools for diagnosis, in the topic of the indebtedness and savings, given the emergence of over indebtedness as a specially relevant issue in the last years. Another relevant issue is savings, given the new incentives created for its development. Both issues constitute different aspects of an effort, in the economical realm, that can be started in the welfare administrations systems of labor institutions.
\end{abstract}

Key words: indebtedness - savings- employee assistance programs - social organizations

Los alcances que en este espacio se efectúan respecto de la realidad del sobreendeudamiento, están basados en fuentes de información provenientes de Estudios de Finalización de Carrera de alumnos de la Escuela de Trabajo Social de la PUC. ${ }^{2}$, junto a otros estudios nacionales.

Además de efectuar un trabajo de recopilación en el tema, se diseñaron algunos instrumentos de apoyo para diagnosticar el problema desde las unidades sociales, autodiagnosticar el problema de sobreendeudamiento y formas comunicativas para difundir y promover sistemas de ahorro en el personal. ${ }^{3}$

En el análisis del tema, se hace necesario realizar una distinción básica respecto de un endeudamiento normal y funcional para poder acceder a los bienes de consumo necesarios en la vida de las personas, de un endeudamiento excesivo, el cual es origen de fuertes tensiones y repercusiones en la vida, de quienes lo sufren. El establecimiento de límites entre "el sano endeudamiento" y "endeudamiento problemático", es un ejercicio que comporta cierto grado de arbitrariedad, como cualquier catalogación, pero útil, en la medida que permite clasificar situaciones de riesgo para los trabajadores sujetos de la atención social.

Al respecto, según los análisis que efectúan las entidades bancarias y financieras, cuando se trata de créditos de largo plazo, como son los hipotecarios, se ha establecido, que lo que la persona puede disponer para el compromiso de pago mensual es el 25\% de sus ingresos familiares. Así, se puede entender que estar endeudados por compromisos mensuales bajo

1 Este artículo ha sido extractado del trabajo de Monckeberg, Isabel "Trabajando la temática económica, un área de acción en la gestión de los bienestares institucionales."Enero 2006. Documento de Trabajo. Escuela de Trabajo Social. Pontificia Universidad Católica de Chile.

2 Ponce, Daniela y Ramirez Viviana. Estudio Descriptivo sobre la Situación de Endeudamiento y Consumo del personal en dos Instituciones de Servicios de la Región Metropolitana, Estudio de Finalización de Carrera de las alumnas de Trabajo Social de la Pontificia Universidad Católica.Agosto 2005. El estudio consideró una población de 343 trabajadores. Se describen y analizan los datos en forma separada para cada organización. Por problemas de limitación de tiempo, y porque no respondía a sus objetivos, las alumnas a cargo del estudio, no efectuaron un análisis conjunto para ambas instituciones.

3 Por razones de espacio, estos elementos no están incluidos en el presente artículo. 
esa suma, es una situación controlada. Tratándose de créditos de consumo, el Servicio Nacional del Consumidor establece como máximo de endeudamiento familiar, montos de pago mensuales equivalentes al $25 \%$ del ingreso familiar mensual. ${ }^{4}$

Forma parte de la misión de las unidades de bienestar, velar por la calidad de vida de los trabajadores y sus familias, y por ello, la protección del trabajador en su "vulnerabilidad económica " es un aspecto esencial de su acción. ${ }^{5}$ La experiencia laboral a través del contacto con personas que viven situaciones que pueden ser catalogadas de sobreendeudamiento, plantea la necesidad de intervenir de alguna forma, ya sea para prevenir, evitar o ayudar a dar solución a quienes viven las repercusiones de un sobreendeudamiento.

Son variadas las repercusiones de este problema, desde la pérdida del control sobre la propia situación económica a repercusiones de índole familiar, por crisis en las relaciones interpersonales, deterioramiento del estado de ánimo o problemas de salud derivados. El ambiente de trabajo también se afecta, al producirse distracciones propias de quien está altamente preocupado de situaciones externas; por alteración de los estados de ánimo, o por la necesidad que se presenta de disponer de tiempos entre las horas de trabajo para solucionar los urgentes problemas financieros. Probablemente el estar muy comprometido económicamente le producirá al trabajador, un descontento con su situación laboral, con el ingreso económico, con el medio en general, todo lo cual puede afectar el rendimiento en una situación de trabajo.

\section{El sobreendeudamiento ${ }^{6}$}

Para distinguir entre situaciones de endeudamiento, respecto de la presencia de sobreendeudamiento, el estudio de referencia consideró la capacidad de pago familiar que tenían los trabajadores al momento del estudio, acotándolo a las deudas de consumo. De acuerdo al concepto del Servicio Nacional del Consumidor (SERNAC), clasificaron como sobreendeudados a los trabajadores que man- tenían pagos mensuales correspondientes a créditos de consumo, por sobre el $25 \%$ de los ingresos mensuales familiares.

Las cifras del estudio muestran, la fuerte presencia del problema en los trabajadores de las instituciones estudiadas, realidad que probablemente es compartida por los trabajadores de diferentes organizaciones laborales, y que es coincidente con los reportes de los trabajadores sociales.

En el endeudamiento estudiado, se incluye las deudas de consumo producto de créditos internos, que se descuentan por planilla de sueldos, y las causadas por endeudamiento externo. El nivel de sobreendeudamiento, o personas que tienen deudas de consumo por sobre el $25 \%$ de los ingresos mensuales familiares es cercano a un $60 \%$.

Considerando el nivel de endeudamiento crítico, el cual corresponde a aquellos que están endeudados, y deben cancelar créditos de consumo, por sobre el 50\% de los ingresos familiares, este es mayor en el sector público, correspondiendo a un 32\% del personal. En la institución privada si bien también es alto este porcentaje, correspondiendo al 26\% del personal.

\begin{tabular}{|l|c|c|}
\hline \multicolumn{3}{|c|}{$\begin{array}{c}\text { Endeudamiento - Sobreendeudamiento en } \\
\text { institución del sector público y en institución } \\
\text { del sector privado. }\end{array}$} \\
\hline Nivel de endeudamiento & $\begin{array}{c}\text { Institución } \\
\text { Pública }\end{array}$ & $\begin{array}{c}\text { Institución } \\
\text { Privada }\end{array}$ \\
\hline $\begin{array}{l}\text { Endeudamiento bajo el 25\% } \\
\text { de los ingresos }\end{array}$ & $39 \%$ & $43 \%$ \\
\hline $\begin{array}{l}\text { Endeudamiento entre 26\% } \\
\text { y 40\% de los ingresos }\end{array}$ & $20 \%$ & $18 \%$ \\
\hline $\begin{array}{l}\text { Endeudamiento sobre 41\% y } \\
50 \% \text { de los ingresos }\end{array}$ & $9 \%$ & $12 \%$ \\
\hline $\begin{array}{l}\text { Endeudamiento "crítico", } \\
\text { sobre el 51\% de los ingresos }\end{array}$ & $32 \%$ & $26 \%$ \\
\hline Total trabajadores & $100 \%$ & $99 \%$ \\
\hline
\end{tabular}

Antecedentes en Ponce, Daniela y Ramirez Viviana. Estudio Descriptivo sobre la Situación de Endeudamiento y Consumo del personal en dos Instituciones de Servicios de la Región Metropolitana, Estudio de Finalización de Carrera de las alumnas de Trabajo Social de la Pontificia Universidad Católica.Agosto 2005.

4 SERNAC. Departamento de Educación. Taller de educación para el consumidor. 2002. Santiago, Chile. Pág. 7. En Estudio Descriptivo sobre la Situación de Endeudamiento y Consumo del personal en dos Instituciones de Servicios de la Región Metropolitana, de Daniela Ponce y Viviana Ramirez. Estudio de Finalización de Carrera. Escuela Trabajo Social. Pontificia Universidad Católica de Chile. Agosto 2005.

5 Monckeberg, Pardo, Isabel. Gestión de bienestar en instituciones y empresas. Operatoria de las unidades de bienestar en la administración de servicios y beneficios. Pontificia Universidad Católica, Escuela de Trabajo Social. Documento de Investigación. 2004.

6 La muestra estudiada en Ponce, Daniela y Ramirez Viviana, op cit, pertenece a dos instituciones de servicio de la Región Metropolitana, una de ellas perteneciente al sector público y otra al sector privado. Se estudió un grupo de trabajadores con un sueldo mensual, inferior a 68,4 UF. En la institución privada se trata de 134 casos, con una edad promedio de 41 años. En la institución pública la muestra se compone de 209 casos, con una edad promedio de 43,5. En ambos casos quienes contestaron la encuesta, son trabajadores que lo hicieron en forma voluntaria y anónima. 
Respondiendo a la interrogante, ien quienes se intensifica el problema del sobreendeudamiento?, son los trabajadores administrativos quienes presentan el problema con mayor intensidad. El $68 \%$ de ellos tendría deudas de consumo por pagar mensualmente por un monto superior a la cuarta parte de los ingresos familiares. En los trabajadores auxiliares y en los técnicos también se denota una alta presencia del problema.

Respecto de la situación económica, el sobreendeudamiento tiene mayor presencia en las personas con menores ingresos familiares. Los grupos económi$\cos \mathrm{E}$ y D que son aquellos con ingresos mas bajos, presentan un sobreendeudamiento del 63 y $60 \%$ de los trabajadores respectivamente. El grupo C3, que representa a quienes tienen ingresos entre \$ 440.001 y $\$ 670.000$, tiene un $46 \%$ de trabajadores sobreeendeudados. El grupo C2, con ingresos sobre esta cifra, tiene un nivel menor de sobreendeudamiento $(34 \%)^{7}$

\section{Los créditos}

La contratación de créditos para adquirir bienes, obtener servicios o para responder a las deudas ya contraídas, presenta varias alternativas. Una primera clasificación permite distinguir las alternativas internas que se originan en la propia institución, de las alternativas externas, disponibles en el mercado a las cuales accede el trabajador. Las otras alternativas de crédito a la cual acceden los trabajadores son netamente externas y sus compromisos son cancelados directamente. De este endeudamiento en las instituciones no se tiene mayor conocimiento.

En el estudio analizado, se abarcó todas las fuentes posibles de crédito, internas y externas. En "préstamos empresa" se incluyeron los variados tipos de préstamos internos. En "Créditos Cajas de Compensación", a aquellos otorgados por estas instituciones y que la empresa asegura el descuento por planilla. Los créditos externos, están referidos a bancos, tarjetas de crédito bancarias, casas comerciales, tarjetas de crédito de casas comerciales, créditos financieras y tarjetas de crédito comercial. Un 27\% de los compromisos de créditos de consumo en el personal que está sobreendeudado, es con el sistema interno (créditos empresa y Cajas de Compensación), en un 32\% corresponde a créditos con el sistema bancario, un 25\% con casas comerciales, y 9\% con sistemas de tarjetas de crédito comercial. Este antecedente fortalece el concepto de que el problema del sobreendeudamiento sobrepasa con creces los límites institucionales.

Cuando se les consulta a los trabajadores respecto de las áreas de consumo a las cuales han ido dirigidos sus créditos, el área vestuario, es el que obtiene las mayores nominaciones. Un 32\% de los trabajadores consultados menciona haber utilizado créditos en los últimos seis meses para efectos de vestuario. El segundo item mencionado es por gastos de salud, en un $27 \%$. Por gastos de alimentación, ha solicitado créditos un $25 \%$ y por educación un $20 \%$ de los trabajadores consultados.

\section{Antecedentes nacionales respecto de los créditos de consumo}

Relevantes antecedentes aporta un estudio efectuado por la Superintendencia de Bancos e Instituciones Financieras, ${ }^{8}$ que incluyó un universo del 90\% del sistema bancario nacional. De este estudio, se releva que el promedio de la deuda personal por consumo en el sistema, era de 79,5 UF. La morosidad de las deudas es baja, para las mujeres es de un 0,9\%, y para los hombres de un $1 \%$. El endeudamiento por consumo es proporcionalmente más alto, en las personas de menores ingresos.

En relación al ingreso líquido de las personas, el endeudamiento promedio es de 2,3 ingresos para el caso de las mujeres y 2,4 ingresos para los hombres. Las personas que se clasifican en el tramo de rentas mas bajas, hasta 19 UF, ${ }^{9}$ habrían estado endeudadas el año 2001, en 4,6 rentas promedio. Las personas que corresponden al tramo de rentas entre 19 y 32 UF, habrían estado endeudadas en el año 2001, en 3,2 rentas promedio. Y aquellas con remuneraciones por sobre las $32 \mathrm{UF}$, en 1,7 rentas promedio.

El estudio mencionado concluye que la participación de las mujeres en el mercado de los créditos es significativa, aunque es inferior al de los hombres, presentando un mejor comportamiento de pago. Su nivel de participación en los créditos es constante en los distintos tramos de edad. En los hombres, en cambio hay una mayor concentración de los créditos a la edad cercana a 30 años.

7 Estos valores están referidos a Junio 2005.

8 Superintendencia de Bancos e Instituciones Financieras. "Deudas de personas en el sistema financiero. Una visión de género". Santiago Chile 2001.

9 Referencia a Octubre 31, 2005. 
Los últimos antecedentes, reflejan un aumento sostenido de las deudas de consumo. El Informe de Estabilidad Financiera del Banco Central, señala que la deuda de consumo bancaria por deudor, en Agosto 2005, es de 2,3 millones de pesos, cifra que es cuatro veces superior a la presentada hace diez años, y 14\% sobre la presentada hace un año, aumento que no es proporcional al aumento de los ingresos económicos de las familias chilenas. ${ }^{10}$

\section{Características del consumo}

A través del consumo, o gastos efectuados por las personas, se satisfacen los distintos tipos de necesidades personales y familiares. Aquellos ingresos que no se destinan al consumo, constituyen ahorro.

La alimentación se presenta en los datos del estudio analizado, como aquella necesidad a la cual se le destina los mayores montos en dinero promedio mensual. En alimentación se destina una cantidad promedio mensual correspondiente a 6,14 UF. En vivienda 5,93 UF. En educación 4,3 UF. En servicios básicos 3, 52 UF. Cantidades promedios menores se destinan a transporte, vestuario, salud, y recreación. ${ }^{11}$

\begin{tabular}{|l|r|r|r|l|}
\hline \multicolumn{5}{|c|}{ Gastos de Consumo } \\
\hline $\begin{array}{l}\text { Gastos de } \\
\text { consumo }\end{array}$ & $\begin{array}{c}\text { Institución } \\
\text { Privada }\end{array}$ & $\begin{array}{c}\text { Institución } \\
\text { Pública }\end{array}$ & Total & Valor UF \\
\hline Alimentación & $\$ 109.826$ & $\$ 106.124$ & $\$ 107.699$ & 6,14 \\
\hline Vivienda & $\$ 105.262$ & $\$ 103.357$ & $\$ 104.167$ & 5,93 \\
\hline Educación & $\$ 79.219$ & $\$ 72.646$ & $\$ 75.442$ & 4,30 \\
\hline $\begin{array}{l}\text { Servicios } \\
\text { Básicos }\end{array}$ & $\$ 67.579$ & $\$ 57.655$ & $\$ 61.877$ & 3,52 \\
\hline Transporte & $\$ 48.021$ & $\$ 43.154$ & $\$ 45.224$ & 2,58 \\
\hline Vestuario & $\$ 39.439$ & $\$ 35.041$ & $\$ 36.912$ & 2,10 \\
\hline Salud & $\$ 29.716$ & $\$ 41.667$ & $\$ 36.583$ & 2,08 \\
\hline Recreación & 19.495 & $\$ 14.118$ & $\$ 16.405$ & 0,93 \\
\hline
\end{tabular}

Antecedentes en Ponce, Daniela y Ramirez Viviana. Estudio Descriptivo sobre la Situación de Endeudamiento y Consumo del personal en dos Instituciones de Servicios de la Región Metropolitana, Estudio de Finalización de Carrera de las alumnas de Trabajo Social de la Pontificia Universidad Católica.Agosto 2005

El consumo para las diferentes necesidades se modifica en forma decreciente a medida que los ingresos son más bajos. Sin embargo hay ciertos gastos como lo son vivienda, y recreación donde se presentan las mayores diferencias de gastos si se considera los grupos económicos de referencia para cada una de las personas estudiadas. También se producen cambios importantes en los gastos de alimentación y educación. En cambio en materias de transporte, salud y vestuario es donde se producen las menores diferencias entre un grupo y otro, siendo en estos aspectos el gasto más similar.

\begin{tabular}{|l|c|c|c|c|}
\hline \multicolumn{5}{|c|}{ Gastos de Consumo por grupo económico } \\
\hline $\begin{array}{c}\text { Gasto } \\
\text { promedio } \\
\text { por grupo } \\
\text { económico }\end{array}$ & Grupo C2 & Grupo C3 & Grupo D & Grupo E \\
\hline Vivienda & $\$ 150.541$ & $\$ 139.874$ & $\$ 46.931$ & $\$ 36.258$ \\
\hline $\begin{array}{l}\text { Servicios } \\
\text { Básicos }\end{array}$ & $\$ 86.068$ & $\$ 59.883$ & $\$ 44.108$ & $\$ 35.089$ \\
\hline Alimentación & $\$ 142.514$ & $\$ 111.466$ & $\$ 81.183$ & $\$ 60.975$ \\
\hline Educación & $\$ 102.493$ & $\$ 75.104$ & $\$ 49.926$ & $\$ 37.500$ \\
\hline Vestuario & $\$ 49.548$ & $\$ 33.563$ & $\$ 29.546$ & $\$ 21.830$ \\
\hline Transporte & $\$ 60.437$ & $\$ 24.118$ & $\$ 32.890$ & $\$ 33.801$ \\
\hline Recreación & $\$ 29.249$ & $\$ 13.204$ & $\$ 7.976$ & $\$ 4.034$ \\
\hline Salud & $\$ 38.635$ & $\$ 38.932$ & $\$ 31.422$ & $\$ 39.911$ \\
\hline
\end{tabular}

Antecedentes en Ponce, Daniela y Ramirez Viviana. Estudio Descriptivo sobre la Situación de Endeudamiento y Consumo del personal en dos Instituciones de Servicios de la Región Metropolitana, Estudio de Finalización de Carrera de las alumnas de Trabajo Social de la Pontificia Universidad Católica.Agosto 2005

Se tienen patrones de consumo diferentes de acuerdo a los ingresos de las personas. Hay rubros como es la alimentación, en que bajan gradualmente los gastos a medida que los ingresos son menores. En cambio el rubro de la salud, el gasto se mantiene en forma muy similar.

\section{Motivos de endeudamiento}

Cuando a las personas se les consulta lo que ha motivado su nivel de endeudamiento, en su mayor parte apela, a su nivel de ingresos. También mencionan como causas los problemas familiares, aspirar a un nivel de vida mejor y a desorden presupuestario. La razón "nivel de ingresos" es coincidente con el

\footnotetext{
10 Mendoza V Luis. Deuda de los hogares chilenos crece más rápido que sus ingresos. Artículo Diario la Tercera. Negocios. 16 diciembre 2005.

11 Los valores están calculados en UF. Los valores en \$ corresponden al mes de Junio 2005.
} 
dato aportado por el cruce de variables entre sobreendeudamiento y niveles de ingreso que reflejó que, estaría más sobreendeudado el sector con menores ingresos.

La razón "problemas familiares", corresponde a un $26 \%$ de los consultados. Este antecedente puede considerarse en cierta medida como el porcentaje de endeudamiento excesivo que se debe más bien a imprevistos, que a situaciones buscadas voluntariamente. Sólo un pequeño porcentaje (8\%) alude a la razón "desorden en el presupuesto familiar". Un $19 \%$, se refiere a otras causas, respecto de las cuales el estudio no entrega mayores antecedentes.

Se estima que las percepciones de las personas sobre el endeudamiento excesivo, se caracterizan por una mirada de dependencia respecto de situaciones externas que son las que ellos sienten que estarían produciendo la situación riesgosa. Perciben que no tienen un mayor control sobre la situación, que es algo que se va produciendo producto de presiones familiares, arrastre de situaciones anteriores, con lo que se denota un comportamiento de poca prevención al respecto. Sólo un pequeño porcentaje realiza un presupuesto familiar mensual, y en su mayoría tienen escasa información al momento de solicitar créditos. Estas razones avalan la interpretación de que el sobreendeudamiento es una situación que no sucede de un día para el otro, sino más bien es un proceso que iría creciendo, de a poco, de acuerdo a distintas situaciones, por lo que no habría una sola razón, que la explique en cada caso.

\section{Aportes de otros estudios en el tema}

En relación a los motivos de sobreendeudamiento, un estudio anterior realizado por alumnas de Trabajo Social de la PUC, en su trabajo de finalización de carrera, ${ }^{12}$ aporta algunos antecedentes de interés de incluir es esta revisión del problema.

En este estudio, referido a un pequeño número de casos, de dos empresas de la Región Metropolitana, de trabajadores que estaban de hecho en condición de sobreendeudados, el 50\% de ellos, manifiesta no cumplir oportunamente con las fechas de pago cuando contrae una deuda. En consecuencia, estas personas además de los intereses que pagan por los créditos, deben afrontar pagos por castigos de morosidad, lo que les intensifica el problema. Tampoco comparten con su familia, la necesidad de adquirir nuevos créditos, lo que produce un empeoramiento de la situación, por cuanto el crédito se contrae en forma individual por parte de cada uno de los integrantes del grupo familiar, no considerándose los compromisos adquiridos por el otro.

En este grupo de estudio, más de un 50\% no era propietario ni adquiriente de una vivienda, lo que muestra la gravedad de su situación; son personas que además de la situación de endeudamiento en que estaban no han dado solución al problema más básico, que es el problema de la vivienda, que requiere ahorro previo y cierta capacidad de endeudamiento.

Interesantes antecedentes entrega un estudio de una Compañía de Seguros. ${ }^{13}$, en que se menciona que uno de cada tres chilenos de los grupos socioeconómicos C3 y D reconoce haber tenido problemas para cancelar sus cuotas de crédito, siendo los más afectados el grupo de personas jóvenes, mencionándose específicamente las edades entre 25 y 34 años.

Señala también el estudio, que el 60\% de los trabajadores dependientes puede mantener sólo hasta tres meses su nivel de gasto en caso de perder su fuente de trabajo. Respecto de las percepciones de riesgo que tienen los chilenos, éstas son las enfermedades catastróficas (93\%), los hechos graves en la familia (89\%) y la posibilidad de quedar desempleado (88\%).

\section{Efectos del sobreendeudamiento}

El sobreendeudamiento, constituye una variable económica caracterizada por el alto riesgo de que las personas puedan no cumplir sus compromisos contraídos. Se trata de una situación de vulnerabilidad desde la perspectiva social, con probables repercusiones en la vida personal, familiar y laboral.

En el estudio analizado, el personal consultado reconoce que el sobreendeudamiento les ocasiona distintos efectos. Un 47\% reconoce sus consecuencias negativas. Aunque esta percepción se da por igual en los trabajadores de la institución pública que privada, los funcionarios públicos son los que

12 Matus, Tamara y Pumero, Andrea. Estudio descriptivo de las características y percepciones del sobreendeudamiento de los trabajadores de dos empresas privadas de la Región Metropolitana. Estudio de Finalización de Carrera. Escuela Trabajo Social. Pontificia Universidad Católica de Chile. Julio 2004.

13 Artículo. Una de cada tres personas tiene problemas para pagar sus créditos.26 de Agosto de 2005.Economía y Negocios, El Mercurio. Se refiere a estudio efectuado por la Aseguradora Cardiff. La muestra de estudio corresponde a 1.002 chilenos mayores de 18 años. 
nombran más efectos negativos, fruto de una situación de sobreendeudamiento.

Los efectos negativos mencionados se refieren al deterioro de las relaciones familiares, apareciendo principalmente el tema de las discusiones en el núcleo familiar así como la alteración en el estado del ánimo. En las personas sobreendeudadas las consecuencias en esta área son más críticas; incluso se da el caso de encuestados que señalaron la ruptura familiar como un resultado negativo de su nivel de endeudamiento.

\section{Los sistemas de cobranza}

Es frecuente que las casas comerciales, bancos y financieras encarguen a compañías externas las deudas que no han sido cumplidas en sus plazos de pagos. Los sistemas para "recordar estos créditos" han sido sujetos de crítica, en cuanto se han convertido en formas de acosar al deudor, no cumpliéndose en algunos casos con las normas legales al respecto, lo que afecta la vulnerabilidad de la propia familia y a su situación laboral. ${ }^{14}$ Legalmente están establecidos los montos máximos de pago, de acuerdo al total de la deuda, una vez que se haya cumplido los 15 días corridos de atraso, desde el vencimiento del pago. ${ }^{15}$

La ley del consumidor normó los procedimientos para las formas de cobranzas no permitiendo apremios y amenazas; prohíbe el envío de documentos que busquen hacer creer al deudor, que son escritos judiciales. No se permiten comunicaciones a terceros ajenos a la obligación en las que se dé cuenta de la morosidad, o visitas o llamados telefónicos al hogar, en horarios que no sean hábiles ${ }^{16}$ y en general, conductas que afecten la privacidad del hogar, la convivencia normal de sus miembros y su situación laboral. ${ }^{17}$ Quien contrata un crédito, tiene derecho a ser informado respecto de la empresa que le cobrará en caso que se retrase el pago, procedimientos y horarios. La ley también le permite pagar directamente al proveedor las cuotas impagas, aunque sea la empresa de cobranza la que se lo haya recordado.
Los reclamos respecto del no cumplimiento de estas normas deben efectuarse al SERNAC, quien puede entablar una demanda judicial. ${ }^{18}$

\section{Otras normas respecto de los deudores morosos}

La normativa legal ha establecido que no puede discriminarse a una persona en un proceso de selección laboral por sus deudas. Sólo puede exigirse el certificado DICOM, cuando por la naturaleza de los servicios que llevan implícitos, tiene especial relevancia conocer la información comercial, financiera o bancaria, para efectos de garantizar al empleador una adecuada decisión al momento de la contratación. Sólo se permite como excepción, tomar conocimiento de los antecedentes indicados, de los trabajadores que tengan poder para representar al empleador, tales como gerentes, subgerentes, agentes o apoderados, siempre que en todos estos casos, estén dotados a lo menos de facultades generales de administración; y de los trabajadores que recauden, administren o custodien fondos o valores de cualquier naturaleza.

\begin{abstract}
Ahorro
El ahorro está constituido por aquella parte del ingreso económico que se decide no destinar al consumo, sino a una inversión, con el fin de generar ingresos futuros.

La conducta de ahorro puede ser considerada un tipo de hábito que las personas sostienen, así como también el sobreendeudamiento, en cierta medida, puede ser considerado un tipo de hábito, en personas que manifiestan esta tendencia.

El ahorro de las familias de menores ingresos, creció en nuestro país sostenidamente en los años 90, realizándose preferentemente a través de las libretas de ahorro del Banco del Estado de Chile. Las motivaciones del ahorro obedecen a la adquisición de una vivienda, al motivo "precaución" y para disponer recursos para la vejez. El fuerte crecimiento que
\end{abstract}

14 Cobranza Judiciales. Las deudas me acosan. Artículo Economía y Negocios. Diario El Mercurio. 26 Octubre 2005.

15 Los montos máximos los estableció la ley Protección de los derechos de los consumidores. Ley 19. 496.

- Para deudas hasta 10 UF, el monto máximo de cobro es el 9\% de esta cantidad.

- Para deudas entre 10 y 50 UF, el monto máximo es el 6\% de esta cantidad.

- Para deudas sobre 50 UF, el monto máximo es el 3\% de esta cantidad.*

16 Se estableció como horario hábil, el horario entre las 8.AM y las 20 horas.

17 Ley 19.496, articulo 37, inciso quinto. Al respecto no son admisibles los llamados telefónicos de cobranza a otras personas del círculo laboral del trabajador deudor.

18 Ver www. Sernac. Cl 
habría experimentado el país, así como el hábito del ahorro en las familias de menores ingresos, explicarían este aumento. ${ }^{19}$

El Banco del Estado, tiene la participación mayoritaria del mercado en el segmento Libretas de Ahorro. Que no se exija saldo mínimo, no se cobren comisiones de administración, que no se requieran saldos mínimos de mantenimiento de cuenta y se tenga acceso cercano desde los distintos lugares del país, explicarían esta preferencia por el Banco Estado en materias de ahorro personal y familiar de las familias de menores ingresos. ${ }^{20} \mathrm{~A}$ nivel latinoamericano Chile destaca como un país que ha implementado programas que incentivan el ahorro, siendo un ejemplo de ello, el programa de subsidio habitacional que premia el ahorro familiar en sus formas de otorgamiento. Sólo Chile tiene en América Latina, políticas explícitas para el fomento del ahorro familiar. ${ }^{21}$

Como variables de influencia en el ahorro familiar de personas con bajos ingresos se señalan diversos factores macro y microeconómicos, institucionales y socioculturales. Serían condiciones que influyen; la disponibilidad de instrumentos de ahorro alternativos, las condiciones de rentabilidad, riesgo y liquidez, la cobertura geográfica de las instituciones financieras, las exigencias de montos mínimos de ahorro, los beneficios adicionales y el desarrollo previo de hábitos de ahorro. ${ }^{22}$

La política económica y social chilena, ha otorgado relevancia a los hábitos de ahorro; al respecto, se constituyó en 1997, una Comisión Nacional del Ahorro, con el objeto de generar propuestas de política financiera y tributaria para promover el ahorro personal y familiar. ${ }^{23}$ De esta Comisión, a partir de un diagnóstico de que el nivel de ahorro privado era insuficiente, surgiría una serie de propuestas, y entre ellas medidas para dinamizar el ahorro previsional, y establecer incentivos tributarios para el ahorro de las personas, a través de una gama amplia de instrumentos financieros. ${ }^{24}$

Un estudio efectuado por el Banco del Estado, señala que el ahorro en cuanto sexo se distribu- ye equitativamente entre hombres y mujeres. En cuanto a edad, un alto porcentaje de los ahorrantes son mayores de 36 años. Provienen en su mayoría del sector asalariado, en segundo lugar de dueñas de casa, y en tercer lugar del sector informal. Las motivaciones para ahorrar son compra de vivien$\mathrm{da}$, contar con medios financieros para enfrentar la vejez, y disponer de un fondo para la educación de los hijos. Se considera que el ingreso es una variable significativa y correlacionada con el ahorro. ${ }^{25}$

\section{Ahorro a través de cuentas de ahorro previsional}

A partir de agosto 2002, los afiliados del sistema previsional deben elegir los fondos en que tienen sus inversiones. El sistema AFP ofrece la opción de cinco tipos de fondos, los cuales disponen distintas combinaciones de instrumentos de inversión, que implican rentabilidades y riesgos distintos para las inversiones, lo que conlleva una necesaria mayor responsabilidad de cada trabajador en la toma de decisiones, lo que afecta su ahorro previsional.

Los fondos de pensiones se diferencian por el porcentaje de recursos que pueden destinar a la compra de instrumentos de renta variable. Las opciones van desde el Fondo E, que sólo invierte en Renta Fija, hasta el Fondo A, que puede mantener hasta un $80 \%$ invertido en títulos de renta variable. Sólo hay restricciones en la elección, por concepto edad, para quienes están más próximos a la edad de jubilación, o que ya están con jubilaciones de retiro programado y sólo son aplicables a la Cuenta de Capitalización Individual Obligatoria.

La edad es un factor importante a considerar en la elección de los fondos. Se espera que una persona joven, que tiene por delante un extenso período de ahorro antes de jubilar, puede invertir su ahorro previsional en un fondo con una mayor proporción en renta variable, sin mayor riesgo, ya que en el largo plazo es probable que se recuperen pérdidas puntuales, obteniendo al final mejor rentabilidad. Pero si se está mas próximo a pensionarse, es acon-

19 Errázuriz, Enrique, Ochoa, Fernando y Olivares Eliana. El ahorro familiar en Chile. Naciones Unidas. Proyecto CEPAL./ Gobierno de Holanda. Politicas financieras para incrementar el ahorro y promover la equidad. Diciembre 2001.

20 Errázuriz, Enrique, Ochoa ,Fernando y Olivares Eliana. Op. Cit.

21 Szlachman, Raquel. Promoviendo el ahorro de los grupos de menores ingresos. Op. Cit.

22 Szlachman, Raquel. Promoviendo el ahorro de los grupos de menores ingresos. Documento Naciones Unidas. CEPAL. Abril 2003.

23 Errázuriz, Enrique, Ochoa, Fernando y Olivares Eliana. Op. Cit.

24 Hachette, Dominique. Comentarios al Informe de la Comisión del Ahorro. Hacia un mayor ahorro privado en Chile. 1998. www. economia.puc.cl/publicaciones/ cuadernos/cuaderno104.htm - 35k - Resultado Suplementario

25 Szlachman, Raquel. Promoviendo el ahorro de los grupos de menores ingresos. Op. Cit.. 
sejable privilegiar la seguridad, y elegir un Fondo de Pensiones con una mayor proporción de renta fija.

Los antecedentes respecto del ahorro en las cuentas de ahorro de las APF, o cuenta dos, son ilustrativos. Un 20\% de los afiliados al sistema tiene una cuenta de este tipo, lo que equivale a más de 1,4 millón de chilenos, según cifras a abril de 2005. Esta es una alternativa de inversión ampliamente utilizada por sectores económicos medios y bajos. En sectores sobre renta tope, en cambio, una cifra cercana al 14\% tiene ahorros en esta cuenta. ${ }^{26}$

Las motivaciones para ahorrar que se presentan en las familias de menores ingresos, están representadas básicamente por la necesidad de adquirir una vivienda, tener los medios financieros para la vejez, lo que se traduce " en no ser carga", enfrentar imprevistos, especialmente el desempleo o emergencias, y también el disponer de un fondo para la educación de los hijos. ${ }^{27}$ Estas situaciones de ahorro se ven afectadas por los ciclos económicos o condiciones económicas del país. En tiempos normales, se describe que uno de cada cinco chilenos ahorra para financiar la compra de un bien, físico o un servicio, y uno de cada tres lo hace por precaución. ${ }^{28}$

Un 31\% de los entrevistados del estudio analizado, manifestó efectuar algún tipo de ahorro, y se dio la relación lógica de que ahorran menos aquellos que son catalogados de sobreendeudados. El estudio no entrega antecedentes de las formas de ahorro que utiliza el personal, ni sus motivaciones específicas.

Si se consideran sólo los datos de ahorro nacional a través del sistema previsional, se tiene que a Junio del año 2005, un $22 \%$ de los cotizantes, lo que incluye trabajadores dependientes e independientes tiene cuentas de ahorro. El ahorro efectuado a nivel nacional se da preferentemente en el Fondo tipo C, el cual corresponde a las características de las inversiones que venía trabajando el sistema AFP antes de la posibilidad de elección de fondos por parte de los usuarios.

A modo de resumen: La contratación de créditos para adquirir bienes, obtener servicios o para responder a las deudas ya contraídas, se origina en la propia institución, y en alternativas externas, disponibles en el mercado. Internamente la mayor parte de los créditos está destinada a la problemática salud. Una importante fuente de crédito, que obedece a diferentes necesidades, son los créditos de Caja de Compensación. En la institución pública, se presentan también, otras fuentes de crédito a las cuales tiene acceso fácil el personal.

Más que con créditos internos, el sobreendeudamiento está comprometido con instituciones externas a las organizaciones laborales. Las razones de los créditos son variadas, siendo el rubro vestuario el que tiene mayor presencia.

En relación a los hábitos de consumo, la alimentación se presenta como aquella necesidad a la cual se le destina los mayores montos en dinero promedio mensual en las personas estudiadas (con remuneraciones de hasta $\$ 1.200 .000$, valor a Junio 2005). El consumo para las diferentes necesidades se modifica en forma decreciente a medida que los ingresos son más bajos. Ciertos gastos como la vivienda, y recreación presentan las mayores diferencias de gastos si se considera los grupos económicos de referencia para cada una de las personas estudiadas. También se producen cambios importantes en los gastos de alimentación y educación. En cambio en materias de transporte, salud y vestuario es donde se producen las menores diferencias entre un grupo y otro, siendo en estos aspectos el gasto más similar.

La percepción de las personas, es que el endeudamiento se debe en su mayor parte a su nivel de ingresos.Las percepciones de las personas sobre el endeudamiento excesivo, se caracterizan por una mirada de dependencia respecto de situaciones externas que son las que ellos sienten que estarían produciendo la situación riesgosa. Perciben que no tienen un mayor control sobre la situación, que es algo que se va produciendo producto de presiones familiares, arrastre de situaciones anteriores, con lo que se denota un comportamiento de poca prevención al respecto.

El sobreendeudamiento, desde la perspectiva social provoca en el trabajador una situación de vulnerabilidad, con repercusiones negativas en la vida personal, familiar y laboral. Trabajar por la prevención de esta situación, y su tratamiento cuando ya se ha hecho presente es un desafío para los bienestares de las organizaciones laborales.

26 García Schilling, Daniel. El 20\% de los afiliados tiene una "cuenta dos" en las AFP. Artículo. Jueves, 08 de Septiembre de 2005. Economía y Negocios, El Mercurio.

27 Errázuriz, Enrique, Ochoa, Fernando y Olivares, Eliana. El ahorro familiar en Chile. Naciones Unidas. CEPAL. Unidad de estudios especiales. Diciembre 2001. Documento disponible Internet.

28 Hunneus Cristóbal. Principales motivaciones de los chilenos para ahorrar: evidencia usando datos subjetivos. Universidad de Stanford. Sin especifcación de año. www.b.central/estpub/estudios/bancocentral/v1.17k. 


\section{Bibliografía}

EL MERCURIO. Economía y Negocios. Artículo. Una de cada tres personas tiene problemas para pagar sus créditos.26 de Agosto de 2005. El Mercurio. Economía y Negocios. Artículo. Cobranzas Judiciales. Las deudas me acosan. 26 Octubre 2005.

GARCÍA, SCHILLING, DANIEL. El Mercurio. Economía y Negocios. El 20\% de los afiliados tiene una "cuenta dos" en las AFP. Artículo. 08 de Septiembre de 2005.

HACHETTE, DOMINIQUE. Comentarios al Informe de la Comisión del Ahorro. Hacia un mayor ahorro privado en Chile. 1998. www.economia.puc. cl/publicaciones/ cuadernos/cuadernol04.htm - 35k - Resultado Suplementario.

HUNNEUS CRISTÓBAL. Principales motivaciones de los chilenos para ahorrar: evidencia usando datos subjetivos. Universidad de Stanford. Sin especificar año. www. b.central/estpub/estudios/bancocentral/v1.17k.

ERRÁZURIZ, ENRIQUE, OCHOA ,FERNANDO Y OLIVARES ELIANA. El ahorro familiar en Chile. Naciones Unidas. Proyecto CEPAL./ Gobierno de Holanda. Políticas financieras para incrementar el ahorro y promover la equidad. Diciembre 2001.

LEY 19.496. www. Sernac. Cl .

MATUS, TAMARA Y PUMERO, ANDREA. Estudio descriptivo de las características y percepciones del sobreendeudamiento de los trabajadores de dos empresas privadas de la Región Metropolitana. Estudio de Finalización de Carrera. Escuela Trabajo Social. Pontificia Universidad Católica de Chile. Julio 2004.
MENDOZA V LUIS. Deuda de los hogares chilenos crece más rápido que sus ingresos. Artículo Diario la Tercera. Negocios. 16 diciembre 2005.

MONCKEBERG, PARDO, ISABEL. Gestión de bienestar en instituciones y empresas. Operatoria de las unidades de bienestar en la administración de servicios y beneficios. Pontificia Universidad Católica, Escuela de Trabajo Social. Documento de Investigación. 2004.

MONCKEBERG, PARDO, ISABEL. La gestión de bienestar en organizaciones laborales y la administración de beneficios y servicios. Pontificia Universidad Católica, Escuela de Trabajo Social. Documento de Investigación. 2005.

PONCE, DANIELA Y RAMIREZ, VIVIANA. Estudio Descriptivo sobre la Situación de Endeudamiento y Consumo del personal en dos Instituciones de Servicios de la Región Metropolitana. Estudio de finalización de Carrera Escuela Trabajo Social. Pontificia Universidad Católica de Chile. Agosto 2005.

SERNAC. Departamento de Educación. Taller de educación para el consumidor. 2002.

SUPERINTENDENCIA DE BANCOS E INSTITUCIONES FINANCIERAS. Deudas de personas en el sistema financiero. Una visión de género. Santiago Chile 2001

SZLACHMAN, RAQUEL. Promoviendo el ahorro de los grupos de menores ingresos. Documento Naciones Unidas. CEPAL. Abril 2003.

Centro de Estudios Públicos. Determinantes del ahorro privado en Chile. Chile 2005. www.cepchile.cl/dms/ lang_1/indice_libro_3083.html

FECHA DE RECEPCIÓN: diciembre 2005

FECHA DE ACEPTACIÓN: marzo 2006 